\title{
Peran aparat kelurahan dan partisipasi masyarakat dalam perencanaan pembangunan di Kelurahan Lalebata
}

\author{
Nurul Fadhilah Majid
}

43182034

\section{nurulfadhilahmajid@gmail.com}

\section{Universitas Muhammadiyah Sidenreng Rappang}

\begin{abstract}
Abstrak
Penelitian ini dilakukan untuk mengetahui bagaimana peran aparat kelurahan dan partisipasi masyarakat kelurahan dalam perencanaan pembangunan titik penelitian ini dilakukan dengan metode studi literatur. Di kelurahan Lalebata memiliki populasi 29101 jiwa . Dengan teknik pengumpulan data yaitu probability sampling titik dengan dengan penelitian ini dapat menjadi acuan dalam mengambil tindakan. hasil penelitian ini menunjukkan peran aparat kelurahan dan partisipasi masyarakat di kelurahan adalah batas sudah baik dalam peribadatan penyusunan perencanaan pembangunan
\end{abstract}

Kata kunci: aparat kelurahan, partisipasi masyarakat, musrembang

A. Pendahuluan

Partisipasi masyarakat dalam kegiatan pemberdayaan masyarakat kurang serta dalam usaha yang telah di kelola oleh pemerintah kelurahan. Dalam pelaksanaan pembangunan partisipasi masyarakat sangat diharapkan dalam setiap tahapan pembangunan yang dimulai dari tahap perencanaan, tahap pelaksanaan, tahap pemanfaatan dan tahap evaluasi. Melalui pembangunan yang berbasis partisipasi masyarakat ini akan dapat dilaksanakan pembangunan daerah yang benar-benar sesuai dengan kebutuhan dan aspirasi masyarakat. Mekanisme perencanaan tersebut dimulai dari kegiatan Musyawarah Perencanaan 
Pembangunan tingkat kelurahan/kelurahan, tingkat kecamatan, tingkat kabupaten, yang selanjutnya di tingkat regional dan nasional. Dalam setiap proses perencanaan pembangunan yang dilaksanakan secara berjenjang diharapkan sesungguhnya adalah adanya peranan aparatur pemerintah dan partisipasi masyarakat. (Ahmad Mustanir1), Kamaruddin Sellang2), Akhwan Ali3), Madaling4), 2018)

Dalam jurnal (1)Zhilviana Sulaeman, 2)Ahmad Mustanir, n.d.) Partispasi masyarakat merupakan suatu proses yangdapat mendukung masyarakat untuk mulai "sadar" akan situasi dan masalah yang dihadapinya serta berupaya mencari jalan keluar yangdapat dipakai untuk mengatasi masalah mereka (memiliki kesadaran kritis). Sumardi (2010:46), mengemukakan bahwa partisipasi adlah peran serta seseorang atau kelompok masyarakat dalam proses pembangunan baik dalam bentuk pernyataan maupun dalam bentuk kegiatan dengan memberi masukan pikiran, tenaga, waktu, keahlian, modal, dan atau materi, serta ikut memanfaatkan dan menikmati hasil-hasil pembangunan.

Peranan aparatur pemerintah kelurahan sangat penting sekali di suatu wilayah, khususnya bagi masyarakat. kelurahan sebagai organisasi yang paling dekat dan berhubungan langsung dengan masyarakat. kelurahan merupakan ujung tombak dalam penyelenggaraan pemerintahan daerah. Aparatur pemerintahan dituntut untuk profesional dan menguasai secara baik pekerjaannya. Dengan adanya dukungan dana yang digulirkan dari pusat tersebut, tidak akan ada artinya tanpa harus didukung dengan peran dan fungsi kepala kelurahan beserta unsur-unsur terkait yang ada dalam sistem pemerintahan kelurahan. Kepala kelurahan selaku pemimpin diharapkan untuk mengarahkan atau memberikan motivasi terhadap aparat pemerintah agar dapat melaksanakan tugasnya dengan baik.

Perencanaan pembangunan adalah proses pengembangan kapasitas masyarakat dalam jangka panjang sehingga memerlukan perencanaan yang tepat dan akurat. Perencanaan ini harus mampu mencakup kapan, di mana dan bagaimana pembangunan harus dilakukan agar mampu mendorong pertumbuhan ekonomi dan sosial secara berkesinambungan. Pemerintah daerah punya kewenangan yang lebih 
dalam perencanaan, pengelolaan anggaran dan pelaksanaan pembangunan. Artinya terjadi perubahan paradigma sistem pemerintahan, baik ditingkat pusat, provinsi, dan daerah.

Berdasarkan uraian di atas maka peneliti mengakat beberapa masalah dari judul "Peran aparat kelurahan dan partisipasi masyarakat dalam perencanaan pembangunan di Kelurahan Lalebata ' yaitu 1. Bagaimana peran pemerintah kelurahan dalam perencanaan pembangunan? 2. Bagaimana partisipasi masyarakat dalam musrembang.

\section{B. Tinjauan Pustaka}

\section{Peran aparat kelurahan}

Gaya kepemimpinan pria dalam organisasi disebut transaksi, sedangkan perempuan lebih suka menggunakan pendekatan partisipasi dimana para bawahan didorong untuk memberikan sumbangsih demi kepentingan organisasi. Selanjutnya perempuan selalu lebih mementingkan hubungan interpersonal, komunikasi, motivasi kerja, berorientasi tugas, dan bersikap lebih demokratis dibandingkan dengan pria yang lebih mementingkaan aspek perancangan strategik dan analisa.

Kepemimpinan menurut Zainuddin (2017:233) dalam (Andi Damis Dadda, Ahmad Mustanir, Andi Nilwana, 2018) adalah kemampuan untuk mempengaruhi orang lain untuk mencapai tujuan dengan antusias, dan mampu memberikan contoh kepada pengikut-pengikutnya lewat proses komunikasi dalam upaya mencapai tujuan organisasi. Kepemimpinan merupakan proses mengarahkan, membimbing dan mempengaruhi pikiran, perasaan, tindakan dan tingkah laku orang lain untuk digerakkan kearah tujuan tertentu. Oleh karena itu kepemimpinan memainkan peranan yang amat penting, bahkan dapat dikatakan amat menentukan dalam suatu pencapaian tujuan yang telah ditetapkan sebelumnya.

Menurut (Adam Latif 1, Irwan2, 2019) Kepala kelurahan selaku pemimpin diharapkan untuk mengarahkan atau memberikan motivasi terhadap aparat pemerintah agar dapat melaksanakan tugasnya dengan baik. Pemimpin masyarakat 
di kelurahan merupakan orang terdepan dalam menggerakkan, menuntun dan mempengaruhi masyarakat. Pemimpin yang baik adalah pemimpin yang mengutamakan tercapainya tujuan bermasyarakat secara maksimal dengan memaksimalkan partisipasi seluruh anggota masyarakatnya. Dengan demikian gaya kepemimpinan yang baik itu adalah yang mampu mendistribusikan wewenang dan tanggung jawab pada masyarakat, tanpa mengurangi partisipasi dan tanggung jawab kepada masyarakat lainnya. Pemerintahan kelurahan harus mampu mempengaruhi masyarakatnya agar bersedia berpartisipasi untuk mencapai tujuan yang telah ditetapkan.

Pemerintah sebagai pihak pertama, berada di tingkat pusat dan daerah berperan sebagai stakeholders utama dari e-Government. Peranan pemerintah dalam konsorsium (pengusaha yang mengadakan usaha bersama) terkait adalah sebagai pihak yang menentukan tujuan, kebijakan, standar, dan pola kerja sama dari segala yang berkaitan dengan perencanaan, penerapan, dan pengembangan konsep e-Government. Menurut (Ahmad Mustanir1), Muhammad Rohady Ramadhan2), M Rais Rahmat Razak3), Lukman4), 2019)

\section{Partisipasi masyarakat}

Menurut (Mardikanto \& Poerwoko, 2015) (Ahmad Mustanir1, Fitriani S1, Khaeriyah Adri1, Andi Ayu Nurnawati1, 2020) Partisipasi masyarakat merupakan perwujudan dari kesadaran dan kepedulian serta tanggung jawab masyarakat terhadap pentingnya pembangunan yang bertujuan untuk memperbaiki mutu hidup mereka, artinya, melalui partisipasi yang diberikan berarti benar-benar menyadari oleh aparat pemerintah sendiri, tetapi juga menunjuk keterlibatan masyarakat yang akan di perbaiki mutu hidupnya.

Partisipasi Masyarakat. Didalam melaksakanan suatu program atau pun suatu badan usaha sangat dibutuhkan pasrtisipasi masyarakat didalam nya agar semua program yang telah di rencakan oleh suatu organisasi bisa berjalan sebagaimana mestinya, selain partisipsi kondisi masyarakat juga sangat berpengaruh didalam keberhasilan program yang telah di rencanakan. Menurut 
Sastropoetro dalam (Mustanir \& Adnan, 2020) Beberapa bentuk partisipasi meliputi :

1. Partisipasi dalam bentuk tenaga adalah partisipasi yang diberikan dalam bentuk tenaga untuk pelaksanaan usaha-usaha yang dapat menunjang keberhasilan suatu program.

2. Partisipasi dalam bentuk dana adalah partisipasi dalam bentuk menyumbang harta benda, biasanya berupa alat-alat kerja Atau perkakas.

3. Partisipasi dalam bentuk informasi. Partisipasi pemberian informasi merupakan transisi antara tidak ada partisipasi dengan penghargaan. Pemberian informasi mengenai hak- hak, tanggung jawab, dan pilihan- pilihan masyarakat adalah langkah pertama menuju partisipasi masyarakat.

Beberapa faktor yang mempengaruhi tingkat partisipasi masyarakat didalam pembangunan kelurahannya seperti tingkat pendidikan, pekerjaan, usia, penghasilan, komunikasi dan kepemimpinannya. Pemimpin masyarakat di kelurahan merupakan orang terdepan dalam menggerakkan, menuntun dan mempengaruhi masyarakat. Pemimpin yang baik adalah pemimpin yang mengutamakan tercapainya tujuan bermasyarakat secara maksimal dengan memaksimalkan partisipasi seluruh anggota masyarakatnya.

Menurut Adisasmita dalam (Ahmad Mustanir1, Fitriani S1, Khaeriyah Adri1, Andi Ayu Nurnawati1, 2020) Partisipasi masyarakat adalah pemberdayaan masyarakat, peran sertanya dalam kegiatan penyusunan perencanaan dan implementasi program/proyek pembangunan, dan merupakan aktualisasi kesedian dan kemauan masyarakat untuk berkorban dan berkontribusi terhadap implementasi pembangunan .

Menurut (Isbandi, 2007) partisipasi masyarakat adalah keikutsertaan masyarakat dalam proses pengidentifikasian masalah dan potensi yang ada di dalam masyarakat, pemililihan dan pengambilan keputusan tentang alternatif solusi untuk menangani masalah, pelaksanaan upaya mengatasi masalah, dan keterlibatan 
masyarakat dalam proses mengevaluasi perubahan yang terjadi. Sedangkan (Adisamita, 2006) dan Slamet dalam (Mustanir, Lubis, and Barisan 2017) partisipasi anggota masyarakat adalah keterlibatan anggota masyarakat dalam proses perencanaan dan implementasi program pengembangan yang dilakukan di dalam masyarakat. Ahmad Mustanir1, Fitriani S1, Khaeriyah Adri1, Andi Ayu Nurnawati1, 2020)

Menurut (Mustanir \& Razak, 2017) dalam jurnalnya mengemukakan tentang lingkup partisipasi dengan bertolak pada urutan proses perencanaan pembangunan, maka secara rinci jenis partisipasi masyarakat dalam pembangunan sebagai berikut: 1) Partisipasi dalam pengambilan keputusan, 2) Partisipasi dalam pelaksanaan kegiatan, 3) Partisipasi dalam pemantauan dan evaluasi pembangunan, 4) Partisipasi dalam pemanfaatan hasil-hasil pembangunan Dalam Undang-Undang No. 25 Tahun 2004 [16]

Sistem Perencanaan Pembangunan Nasional mengartikan "partisipasi masyarakat adalah keikutsertaan masyarakat untuk mengakomodasikan kepentingan mereka dalam proses penyusunan rencana pembangunan"

Indikator Partisipasi Masyarakat menurut Mubyarto dalam (Ahmad Mustanir, 2016)adalah:

a) Terlibat memikul tanggung jawab pelaksanaan pembangunan

b) Musyawarah perencanaan pembangunan

c) Pelaksana hasil perencanaan pembangunan

d) Kesediaan membayar iuran sebagai dana swadaya

e) Kesediaan masyarakat dalam menyumbang material seperti pasir, batu bata, semen

Menurut (1Ahmad Mustanir, 2018) Pendekatan partisipatif dilakukan dengan seberusaha mungkin melibatkan semua elemen masyarakat dan 
stakeholders dalam berbagai perencanaan pembangunan termasuk kegiatan Musyawarah Perencanaan Pembangunan (Musrenbang).

\section{Musrembang}

Menurut (Ahmad Mustanir1), Kamaruddin Sellang2), Akhwan Ali3), Madaling4), 2018) Mengemukakan Musrenbang adalah sebuah mekanisme perencanaan, sebuah institusi perencana yang ada di daerah dan sebagai mekanisme untuk mempertemukan usulan/kebutuhan masyarakat (bottom up planning) dengan apa yang akan diprogram pemerintah (tp down planning)

Musrenbang diselenggarakan untuk mensinkronkan berbagai kebutuhan masyarakat yang diperoleh dari forum musyawarah perencanaan pada tingkat dibawahnya sehingga menjadi suatu usulan yang terpadu Pelaksanaan Musrenbang yang berjenjang mulai dari tingkat kelurahan/kelurahan, kecematan, kabupaten/kota, propinsi, hingga dibawa ke tingkat nasional merupakan kesempatan emas bagi masyarakat untuk dapat terlibat perencanaan pembangunan. Akan tetapi dalam penyelenggaraannya kerap kurang memperhatikan aspek partisipasi secara luas, dan masih terbatas pada seremonial dan acara rutin belaka.

Perencanaan pembangunan sendiri merupakan sebuah proses pengembangan kapasitas masyarakat dalam jangka panjang sehingga memerlukan perencanaan yang tepat dan akurat. Perencanaan ini berarti harus mampu mencakup kapan, di mana dan bagaimana pembangunan harus dilakukan agar mampu merangsang pertumbuhan ekonomi dan sosial masyarakat secara berkesinambungan. Perencanaan pembangunan daerah yang bersifat desentralisasi membuka era baru bagi pemerintahan daerah. Dimana dalam Sistem Perencanaan Pembangunan Nasional Indonesia saat ini menggunakan dua pendekataan top down dan bottom up tujuannya untuk menjamin keseimbangan antara prioritas nasional dengan aspirasi prioritas lokal, walaupun pada kenyataanya sebagian besar daerah belum mengakomodasi aspirasi lokal dikarenakan sebagian besar program yang diajukan berdasarkan aspirasi lokal telah tersingkir dalam rapat kordinasi yang menempatkan proposal yang diajukan oleh tingkat pemerintahan yang lebih tinggi 
tanpa memperhatikan proposal yang diajukan oleh tingkat pemerintahan yang lebih rendah. (Mustanir \& Yasin, 2018)

\section{Meteodologi}

Penelitian ini menggunakan tipe kualitatif dan jenis penelitian menggunakan deskriptif karena akan memberikan gambaran keadaan dari objek penelitian sesuai dengan yang ada di lapangan tentang kebijakan pemerintahan kelurahan terhadap partisipasi masyarakat dalam perencanaan pembangunan (Sugiyono, dalam Mustanir, Latif, et al., 2019).

Populasi dalam penelitian ini adalah sebanyak 29101 jiwa keluarga dari keseluruhan jumlah penduduk, yang berdasarkan sumber data yang ada.Dimana teknik penarikan sampel yang digunakan adalah non porobability sampling yaitu dengan purposive sampling.

Teknik pengumpulan data dalam penelitian ini adalah :Observasi, dan Study LiteratureReview (Library Research). Pendekatan yang digunakan pada penelitian ini yaitu dengan menggunakan pendekatan literature. Dalam melakukan pengumpulan data, peneliti mengumpulkan data dan sumber informasi yang berhubungan dengan analisis kebijakan deliberatif dan perencanaan pembangunan melalui data-data pendukung yang bersumber dari jurnal penelitian yang relevab, artikel, buku-buku penunjang, surat kabar dan majalah, ulasan, rangkuman, dan pemikiran penulis tentang beberapa sumber pustaka (slide, informasi dari internet, data gambar dan grafik dan lain lain) tentang topik yang dibahas. (Hariyanti \& Wirapraja, 2018)

\section{Hasil dan pembahasan}

Partisipasi masyarakat dalam mengikuti rapat Musrembang di Kelurahan Lalebata dikategorikan sangat baik. Pelibatan masyarakat dalam pembangunan sudah tentu mutlak adanya, disamping merangkul keikutsertaan masyarakat itu sendiri, partisipan yang diberikan secara tidak langsung memberi peningkatan kapasitas program yang dijalankan, maupun bagi masyarakat itu sendiri. 
Musrembang merupakan agenda tahunan di mana warga saling bertemu mendiskusikan masalah yang mereka hadapi dan memutuskan prioritas pembangunan jangka pendek. Pelaksanaan hasil keputusan rapat pembangunan di kelurahan Lalebata dikategorikan baik. Aparat kelurahan sudah melaksanakan tugasnya secara baik dengan melibatkan masyarakat dalam peencanaan pembangunan

Dalam menentukan kesepakatan proritas kebutuhan sebagaimana di atas dihasilkan tiga kesepakatan yang akan menjadi proritas yaitu: Menyepakati proritas kegiatan yang akan dilaksanakan oleh kelurahan dan merawat yang dibangun dengan penuh disiplin dari integrasi pribadi adalah tanggung jawab serta menyepakati proritas masalah daerah yang ada di kelurahan yang menjadi kewenangan pemerintah daerah maupun pusat dan akan pada Musrembang.

Partisipasi masayarakat dalam masyarakat dalam mengavaluasi hasil pembangunan yang telah di lakukan di kelurahan Lalebata dikategorikan baik. Membangun sesuatu adalah keberhasilan, berdasarkan akumulasi maka diketahui bahwa pembangunan infrasturuktur di kelurahan Lalebata Kabupaten Sidenreng Rappang di kategorikan baik.

\section{E. KESIMPULAN}

Berdasarkan dengan hasil penelitian maka adapun simpulan yang dapat kami kemukakan, sebagai berikut:

1. Partisipasi masyarakat di kelurahan Lalebata Kecamatan Panca Rijang Kabupaten Sidenreng Rappang dikategorikan baik, indikator yang mempunyai nilai tertinggi adalah partisipasi masyarakat dalam mengikuti rapat musrembang (Partisipasi dalam proses pembuatan Keputusan ). Pembangunan infrastruktur di kelurahan Lalebata kecamatan Panca Rijang Kabutan Sidenreng Rappang dikategorikan baik. Peranan partisipan terhadap pembangunan infrastruktur di kelurahan Lalebata Kecamatan Panca Rijang Kabupaten Sidenreng Rappang dikategorikan baik.

\section{DAFTAR PUSTAKA}


1)Zhilviana Sulaeman, 2)Ahmad Mustanir, 3)Andi Ilham Muchtar. (n.d.). Partisipasi masyarakat terhadap perwujudan good governance di kelurahan damai kecamatan watang sidenreng kabupaten sidenreng rappang. 7, 88-92.

1Ahmad Mustanir, 2Muhammad Rusdi. (2018). Participatory Rural Appraisal ( PRA ) Sebagai Sarana Dakwah Muhammadiyah Pada Perencanaan Pembangunan Di Kabupaten Sidenreng Rappang. 1-9.

Adam Latif 1, Irwan2, A. M. (2019). Analisis Kepemimpinan Terhadap Optimalisasi Masyarakat Pada Perencanaan Pembangunan Di Enrekang. 120. https://doi.org/10.20956/xxxxxx

Ahmad Mustanir, D. (2016). Implementasi kebijakan dana kelurahan dan partisipasi masyarakat dalam pembangunan di kelurahan teteaji kecamatan tellu limpoe kabupaten sidenreng rappang. 04(2).

Ahmad Mustanir1, Fitriani S1, Khaeriyah Adri1, Andi Ayu Nurnawati1, G. G. (2020). Sinergitas Peran Pemerintah kelurahan dan Partisipasi Masyarakat Terhadap Perencanaan Pembangunan di Kabupaten Sidenreng Rappang. 1(2), 84-108.

Ahmad Mustanir1), Kamaruddin Sellang2), Akhwan Ali3), Madaling4), M. (2018). PERANAN APARATUR PEMERINTAH kelurahan DAN PARTISIPASI MASYARAKAT DALAM MUSYAWARAH PERENCANAAN PEMBANGUNAN DI kelurahan TONRONGNGE KECAMATAN BARANTI KABUPATEN SIDENRENG RAPPANG. 2(1), 67-84.

Ahmad Mustanir1), Muhammad Rohady Ramadhan2), M Rais Rahmat Razak3), Lukman4), S. T. (2019). Peranan camat dan komunikasi pemerintahan terhadap perencanaan pembangunan di kecamatan malua kabupaten enrekang. 2(2), 94-114.

Andi Damis Dadda, Ahmad Mustanir, Andi Nilwana, J. (2018). Pengaruh Kepemimpinan Lurah PerempuanTerhadap Stabilitas kamtibmas Di kelurahan Rappang Kabupaten Sidenreng Rappang. 1-6. 
Mustanir, A., \& Adnan, A. A. (2020). ISSN 2656-2790 (online). 2(2), 56-65.

Mustanir, A., \& Razak, M. R. R. (2017). Nilai Sosial Budaya Pada Partisipasi Masyarakat Etnik Towani Tolotang Dalam Musyawarah Rencana Pembangunan. (September), 8-9.

Mustanir, A., \& Yasin, A. (2018). Transect Pada Perencanaan Pembangunan Partisipatif. 8(2), 21-31. 